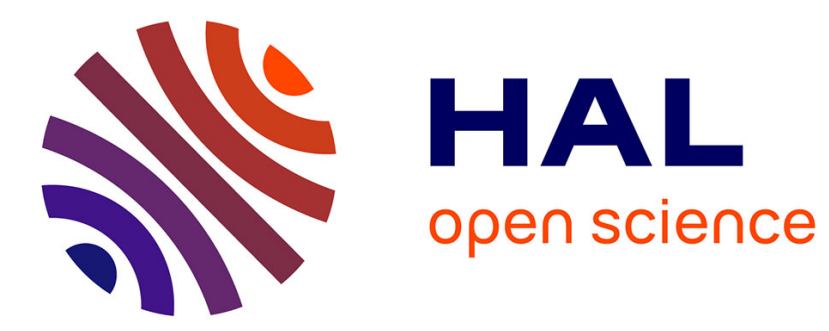

\title{
Electrical properties of short period InAs/GaSb superlattice.
}

Philippe Christol, L. Konczewicz, Yvan Cuminal, Jean-Baptiste Rodriguez, André Joullié

\section{- To cite this version:}

Philippe Christol, L. Konczewicz, Yvan Cuminal, Jean-Baptiste Rodriguez, André Joullié. Electrical properties of short period InAs/GaSb superlattice.. 2006. hal-00103689v2

\section{HAL Id: hal-00103689 https://hal.science/hal-00103689v2}

Preprint submitted on 5 Oct 2006 (v2), last revised 2 Apr 2018 (v3)

HAL is a multi-disciplinary open access archive for the deposit and dissemination of scientific research documents, whether they are published or not. The documents may come from teaching and research institutions in France or abroad, or from public or private research centers.
L'archive ouverte pluridisciplinaire HAL, est destinée au dépôt et à la diffusion de documents scientifiques de niveau recherche, publiés ou non, émanant des établissements d'enseignement et de recherche français ou étrangers, des laboratoires publics ou privés. 


\title{
Electrical properties of short period InAs/GaSb superlattice.
}

\author{
P. Christol $^{* 1}$, L. Konczewicz ${ }^{2}$, Y. Cuminal ${ }^{1}$, H. Aït-Kaci ${ }^{1}$, J.B. Rodriguez ${ }^{1}$, and A. Joullié ${ }^{1}$ \\ ${ }^{1}$ Institut d'Electronique du Sud (IES-CEM2), UMR CNRS 5507, Case 067, Université Montpellier 2, \\ 34095 Montpellier cedex 05, France. \\ 2 Groupe d'Etude des Semiconducteurs (GES), UMR CNRS 5650, Case 074, Université Montpellier 2, \\ 34095 Montpellier cedex 05, France.
}

Received zzz, revised zzz, accepted $z z z$

Published online $z \mathrm{zz}$

PACS 72.40.+w, 73.21.Cd, 73.40.Kp, 73.50.Dn

Electrical properties in the temperature range between $80 \mathrm{~K}$ and $300 \mathrm{~K}$ of type-II short period InAs/GaSb superlattice (SL) photodiode are reported. Resistivity and Hall measurements have been carried out on a 300 periods unintentionally doped SL grown on semi-insulating GaAs substrate while capacitance-voltage and current-voltage measurements have been performed on the same SL structure elaborated on n-type GaSb substrate. Whatever the electrical investigations, the behaviour of the InAs/GaSb SL versus temperature exhibited a reproducible change in type of conductivity. The SL is n-type at high temperatures range with $\mathrm{n}(300 \mathrm{~K})=6 \times 10^{16} \mathrm{~cm}^{-3}$ whereas it is p-type at low temperatures with $\mathrm{p}(100 \mathrm{~K})=2 \times 10^{16} \mathrm{~cm}^{-3}$. This versatile change in type of conductivity is attributed to the presence of inserted InSb layer at the InAs-GaSb interface.

\section{Introduction}

InAs/GaSb superlattice (SL) system is an attractive quantum system for infrared (IR) detection devices thanks to several theoretical advantages induced by its unique type II broken gap band alignment [1]. Indeed, in this misaligned configuration, the effective band gap can be easily tailored by adjusting the layer thicknesses in order to reduced Auger recombination rate in comparison with bulk materials and to cover a wide range of wavelengths including the 3-5 $\mu \mathrm{m}$ mid-wavelength infrared (MWIR) and the 8-12 $\mu \mathrm{m}$ long wavelength infrared (LWIR) atmospheric windows [2]. This last feature can be exploited for the realization of expected multicolor detection module. InAs/GaSb SL p-i-n photodiodes with noticeable detection performances were firstly reported for the LWIR domain [3-5] and more recently in the MWIR spectral range [6, 7] with, in particular, a thermal imaging demonstration by using a focal plane array camera with 256x256 detector elements [8]. Nevertheless, improvement of device technology [9, 10] as well as better knowledge on fundamental properties of this binary/binary SL photodiodes [11, 12] are still necessary to reach the criteria of third generation IR detectors [13].

In this paper, we report on results of electrical properties of short period InAs/GaSb SL adapted for detection in the MWIR domain. The objective of this work is to examine the behaviour of the $\operatorname{InAs} / \mathrm{GaSb}$ SL as a function of temperature, exhibiting a reproducible change in type of conductivity.

\section{InAs/GaSb superlattice samples description}

Two kinds of samples were fabricated by molecular beam epitaxy (MBE). InAs/GaSb non-intentionallydoped (nid) SL structures were grown on semi-insulating (001) GaAs substrate to perform hall meas-

\footnotetext{
" Corresponding author: e-mail: Philippe.Christol@univ-montp2.fr, Phone: +33 46752 43 68, Fax: +33 467544842
} 
urement and on n-type (001) GaSb for current-voltage and capacitance-voltage investigations. Whatever the substrate, the SL's period is composed by equal number N=10 of InAs and GaSb monolayers (MLs) including one InSb ML at the InAs-GaSb interface. The aim of the inserted InSb layer is to eliminate the "GaAs-like" interface and to compensate the tensile effect of the InAs layers in order to achieve SL structure lattice matched to the GaSb substrate. This "GaSb" strain compensated SL structure exhibits room temperature cut-off energy near $220 \mathrm{meV}(5.6 \mu \mathrm{m})$ [14].

For the sample on GaAs substrate, a $500 \mathrm{~nm}$ GaAs buffer layer was grown before the nid SL while a $500 \mathrm{~nm}$ Te-doped GaSb buffer layer was inserted in the case of n-type GaSb substrate. The nid short period SL is composed of 300 periods, corresponding to a total active zone thickness of $1.92 \mu \mathrm{m}$, and the cap layer was already made by the last GaSb layer of the nid SL.

Further details of the epitaxial growth and GaSb(10MLs)/InAs(10MLs)/InSb(1ML) SL structural characterizations have been previously published [14]. Figures 1a and 1b report high-resolution X-ray diffraction spectra of 300 periods SL structure grown on GaAs and GaSb substrates, respectively.
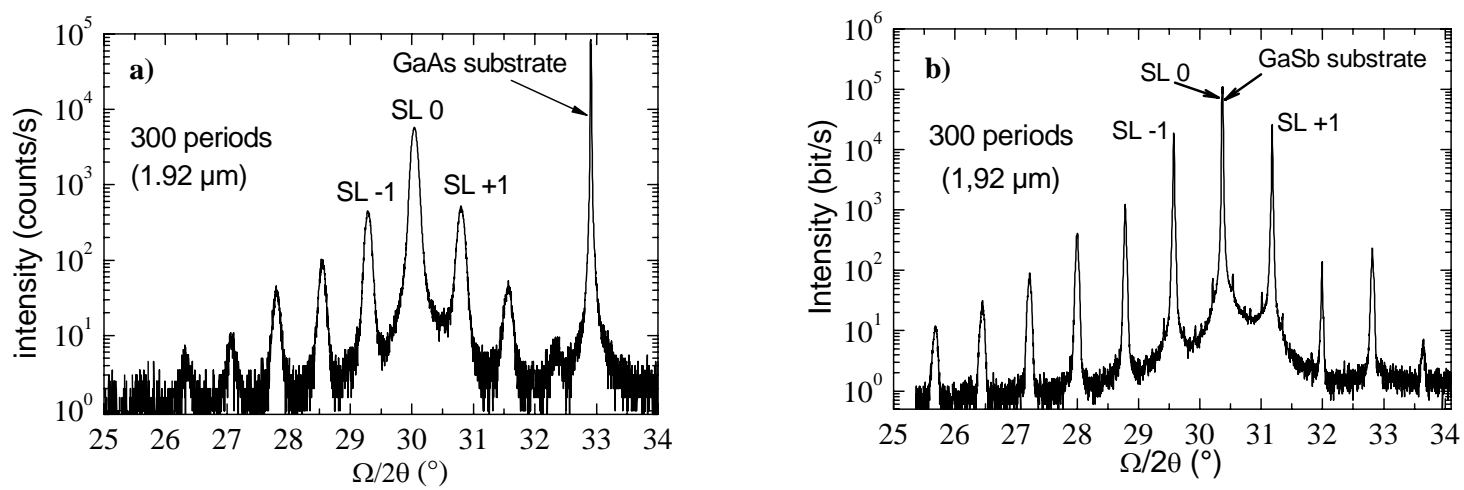

Fig. 1. High-resolution X-ray diffraction pattern of the GaSb(10MLs)/InAs(10MLs)/InSb(1ML) SL structures grown on GaAs substrate (a); on GaSb substrate (b).

In the case of the SL structure grown on GaSb substrate (Fig. 1b), X-ray diffraction rocking curve reveals many intense satellite peaks attesting a good crystalline quality of the layers and the zeroth-order SL peak position indicates that the SL is practically lattice matched $(-0.03 \%)$ to the GaSb substrate. Comparison with curve simulation leads to a measured period of $63.56 \AA$ very close to the intended period of $64 \AA$. Because of the discrepancy between the average lattice constant of the SL and the lattice constant of the GaAs substrate (-7.2\%), the X-ray diffraction peaks observed in Fig.1a are less intense but numerous since up to five satellite peaks can be noted.

\section{InAs/GaSb superlattice electrical properties}

Resistivity and Hall measurements have been performed on the nid GaSb/InAs/InSb SL grown on semiinsulating GaAs substrate to determine the number and type of conduction channels in the SL. Measurements have been done as a function of temperature (77-300K) for magnetic fields in the [0-1] Tesla range. Temperature dependence of apparent carrier concentration and Hall mobility is presented in Fig. 2. A reproducible change in type of conductivity of the nid SL is noted at around 190K (Fig2a) and carrier mobility increases at low and high temperature (Fig.2b). The SL is n-type at high temperatures range with $\mathrm{n}(300 \mathrm{~K})=6 \times 10^{16} \mathrm{~cm}^{-3}$ and a mobility of $1800 \mathrm{~cm}^{2} / \mathrm{V}$.s while it is p-type at low temperatures with $\mathrm{p}(100 \mathrm{~K})=1.5 \times 10^{16} \mathrm{~cm}^{-3}$ with a poor mobility value of $100 \mathrm{~cm}^{2} /$ V.s. This change in conductivity of undoped SL was already observed and reported but at lower temperature 140K [15].

The residual doping in SLs is commonly attributed to the compensation of majority carriers from the individual SL layers [16]. Whatever the temperature, InAs and InSb are residual n-type, while GaSb is ptype. The residual doping in GaSb(10MLs)/InAs(10MLs)/InSb(1ML) SL is therefore induced by the compensation, as function of temperature, of donors in the InAs and InSb layers and acceptors in the 
GaSb layer. Concerning carrier mobility value that increases with temperature, it could be due to the influence of ionised centres caused by the inserted InSb layer at the InAs-GaSb interface [15].

Figure 3 displays resistivity results versus 1/kT. The data show the temperature dependence of the resistivity with two well-defined slopes below and above 190K. From these two regimes, we can extract two thermal activation processes characterized by the activation energies $\mathrm{Ed}=29 \mathrm{meV}$ and $\mathrm{Ed}=136 \mathrm{meV}$ at low and high temperatures, respectively. These two values strongly suggest the influence of deep levels or traps in such type-II SL structure [17]. At low temperature, the SL is p-type because acceptor traps dominate the carrier generation and recombination mechanisms through the traps. At higher temperature, deep donor traps can then be activated leading to an n-type SL structure, especially at room temperature.

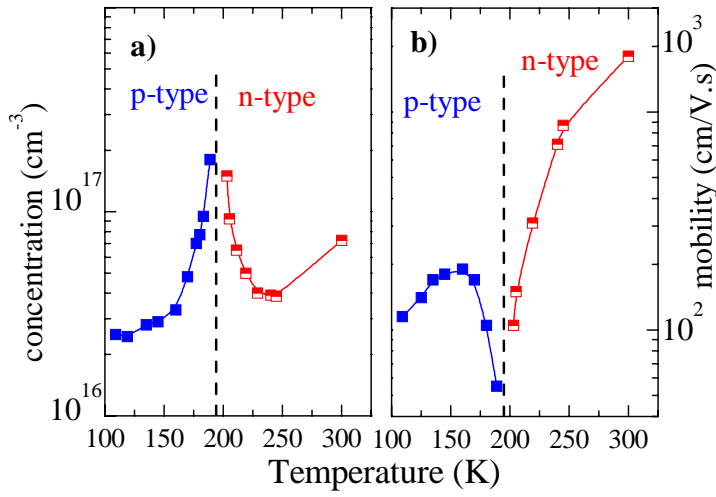

Fig.2: Measured carrier concentration (a) and Hall mobility (b) of the nid SL versus temperature. The Hall coefficient converts from p-type at low temperature to n-type at around $190 \mathrm{~K}$.

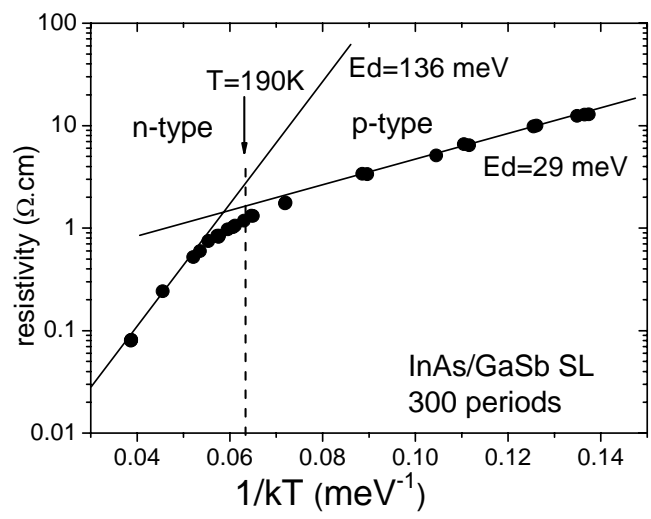

Fig.3: Resistivity versus inverse temperature showing two regimes with two activation energies at low $(\mathrm{Ed}=29 \mathrm{meV})$ and high $(\mathrm{Ed}=136 \mathrm{meV})$ temperatures.

In order to validate such previous observations, another kind of electrical investigations were planned. Mesa devices, shown in insert of Fig. 4a, were prepared with the nid SL structure grown on n-type GaSb substrate $\left(1 \times 10^{18} \mathrm{~cm}^{-3}\right)$, by using standard photolithography and wet etching techniques. AuIn and AuGeNi ohmic contacts have been realized and the diodes were not passivated.
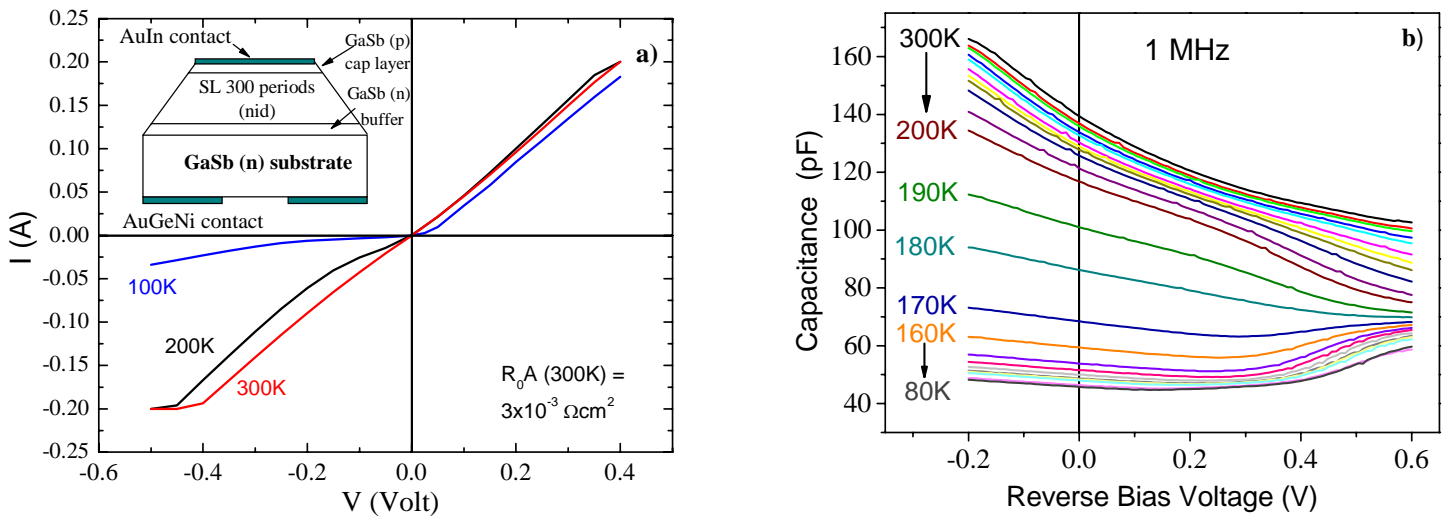

Fig.4: I-V curves (a) and C-V curves (b) of SL mesa diode performed at several temperatures.

Figure 4 presents the current-voltage (I-V) and capacitance-voltage $(\mathrm{C}-\mathrm{V})$ characteristics measured at several temperatures for a device of $350 \mu \mathrm{m}$ diameter. The device shows rectifying characteristic at low temperature (Fig. 4a) until $\mathrm{T}=200 \mathrm{~K}$ but important leakage currents deteriorate the $\mathrm{I}-\mathrm{V}$ curves at higher temperatures. In forward bias, we can note that the SL energy gap is slightly dependent of the temperature, signature of a broken gap band alignment. None indications about the residual SL's type of doping 
can be deduced from these curves. The same is true for the $\mathrm{C}-\mathrm{V}$ measurements, but we can easily observe the change in slope of $\mathrm{C}-\mathrm{V}$ curves versus temperature (Fig. 4b) exhibiting anomalous behavior below 190K, that it could be ascribed to the reverse polarity induces by change in type of conductivity of the SL structure.

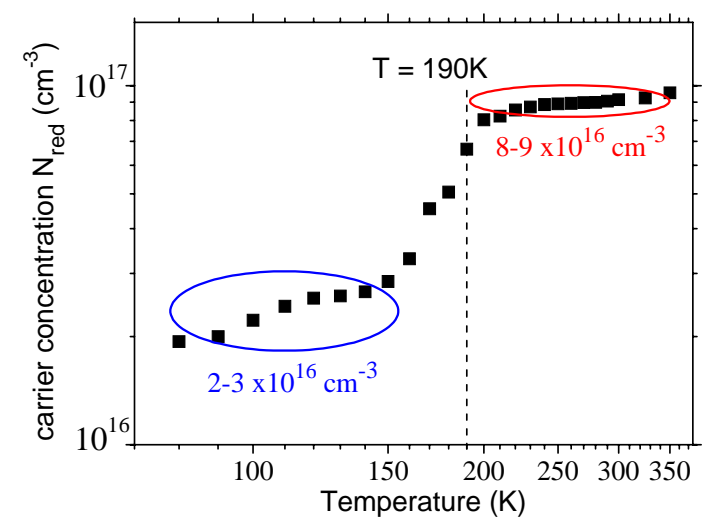

Fig.5 : Reduced carrier concentration $\mathrm{N}_{\text {red }}$ of the undoped SL versus temperature.
From linear $\mathrm{C}-\mathrm{V}$ data, we can extract the reduced carrier concentration $\mathrm{N}_{\text {red }}$ by using [16]:

$$
\left(\frac{A}{C(V)}\right)^{2}=\frac{2 V_{d}}{q \varepsilon_{r} \varepsilon_{0} N_{\text {red }}}-\frac{2}{q \varepsilon_{r} \varepsilon_{0} N_{\text {red }}} V
$$

where $A$ is the area and $V_{d}$ is the built-in potential of the diode $; \varepsilon_{\mathrm{r}}$ is the relative effective dielectric constant value of the multiplayer SL taken equal to 15.4. Figure 5 shows the temperature dependence of $\mathrm{N}_{\text {red }}$. In the case of depletion at an $\mathrm{np}$ or pn junction, $\mathrm{N}_{\text {red }}$ represents the lower carrier concentration without precisions concerning the polarity of the carrier background of the nid SL region. However, these measurements confirm previous Hall results with a carrier concentration at around $2-3 \times 10^{16} \mathrm{~cm}^{-3}$ at low temperature and around $8-9 \times 10^{16} \mathrm{~cm}^{-3}$ above $200 \mathrm{~K}$.

\section{Conclusions}

Electrical measurements (Hall effect, I-V and C-V) performed on short-period InAs/GaSb SL have been reported in the temperature range between $80 \mathrm{~K}$ and $300 \mathrm{~K}$. The nid InAs/GaSb SL reveals an unsettling change in type of conductivity. The SL is p-type at low temperature below $190 \mathrm{~K}$ while is n-type at higher temperature. The control of residual carrier concentration and the accurate understanding of the versatile $\mathrm{p}$ or $\mathrm{n}$-type behaviour of the SL active region is a key point on the way to improve InAs/GaSb system for mid-infrared detection.

\section{References}

[1] D.L. Smith and C. Mailhiot, J. Appl. Phys. 62, 2545 (1987).

[2] M. Razeghi and H. Mohseni, Handbook of Infrared Detection Technologies, M. Henini and M. Razeghi editors, (Elsevier Sciences Ltd, Oxford, 2002) p. 191.

[3] M.J. Yang and B.R. Bennett Electron. Lett. 30, 1710 (1994).

[4] H. Mohseni, E. Michel, J. Sandoen, M. Razeghi, W. Mitchel and G. Brown, Appl. Phys. Lett. 71, 1403 (1997).

[5] H. Mohseni and M. Razeghi, IEEE Photon. Technol. Lett. 13, 517 (2001).

[6] J.B. Rodriguez, P. Christol, A. Ouvrard, F. Chevrier, P. Grech and A. Joullié, Electron. Lett. 41, 362 (2005).

[7] Y. Wei, A. Hood, H. Yau, A. Gin, M. Razeghi, M.Z. Tidrow, V. Nathan, Appl. Phys. Lett. 86, 233106 (2005).

[8] M. Walther, J. Schmitz, R. Rehm, S. Kopta, F. Fuchs, J. Fleissner, W. Cabanski and J. Ziegler, J. Crystal Growth 278, 156 (2005)-161

[9] A. Gin, Y. Wei, A. Hood, A. Bajowala, V. Yazdanpanah, M. Razeghi, M. Tidrow, Appl. Phys. Lett. 84, 2037 (2004).

[10] R. Rehm, M. Walther, F. Fuchs, J. Schmitz and J. Fleissner, Appl. Phys. Lett. 86, 173501 (2005).

[11] D. Hoffman, A. Hood, E. Michel, F. Fuchs and M. Razeghi, IEEE J. Quantum Electron. 42, 126 (2006).

[12] A. Hood, D. Hoffman, Y. Wei, F. Fuchs and M. Razeghi, Appl. Phys. Lett. 88, 052112 (2006).

[13] A. Rogalski A and P. Martyniuk, Infrared Phys. Technol. 48, 39 (2006).

[14] J.B. Rodriguez, P. Christol, L. Cerutti, F. Chevrier and A. Joullié, J. Crystal Growth 274, 6 (2005).

[15] H. Mohseni H, V.I. Litvinov V I and M. Razeghi M, Phys. Rev. B 58, 15378 (1998).

[16] L. Bürkle, F. Fuchs, J. Schmitz and W. Pletschen, Appl. Phys. Lett. 77, 1659 (2000).

[17] J. Shen, S.Y. Ren and J.D. Dow, Phys. Rev B 46, 6938 (1992). 